\title{
Sua doação é meu negócio: uma etnografia em um empreendimento de crowdfunding brasileiro
}

\author{
Louise Scoz Pasteur de Faria
}

O mercado de tecnologia é imaginado como uma sucessão quase vertiginosa de novidades. Novos produtos, novos serviços e até mesmo novos mercados passaram a inundar nosso cotidiano de tal forma que a palavra inovação, muitas vezes quase sinônimo de tecnologia, tornou-se lugar-comum para falar inclusive sobre a própria economia.

A relação entre tecnologia e economia vai além do horizonte da flexibilização do trabalho, de financeirização e introdução de modelos de negócio, produtos e serviços em circuitos cada vez mais amplos de consumo. Falar sobre inovação é também falar sobre como imaginamos o mundo contemporâneo, sobretudo a própria economia e sua relação com a vida cotidiana e com a dimensão da subjetividade, do sonho e do desejo. No entanto, as implicações concretas da gramática da inovação ${ }^{1}$ podem ser muitas vezes obscurecidas exatamente por causa da naturalidade com que as pessoas passaram a lidar com a ideia do novo como algo bom em si mesmo.

Muitos dos debates contemporâneos no campo da antropologia econômica são situados a partir de espaços de produção de inovação tecnológica, econômica e empresarial. Influenciados por estudos sociais das ciências, vários pesquisadores vêm descrevendo etnograficamente as práticas burocráticas, estatais, técnicas e corporativas através das quais os objetos e sujeitos da economia são construídos ${ }^{2}$. O pano de fundo é uma preocupação com a crescente complexidade do quadro econômico, financeiro e produtivo contemporâneo, especialmente no que toca a políticas neoliberais, à expansão do capital especulativo e a mudanças na malha produtiva global.

Isso representa um importante deslocamento teórico em relação aos debates clássicos da antropologia econômica, que consolida sua trajetória epistemológica a partir de reflexões sobre o paradigma

\footnotetext{
1 Entendo como gramática uma matriz a partir da qual racionalidades e afetos são postos em jogo.

2 Autores como Karen Ho (2009); Douglas Holmes (2014); Hirokazu Miyazaki (2013); Aihwa Ong e Stephen Collier (2005); Annelise Riles (2011); Emil Royvik (2011).
} 
da dádiva e de debates articulados em torno das definições formalista e substantivista da economia, nos quais Karl Polanyi (1994) teve papel preponderante.

Esses estudos trabalham com a idéia da economia como performance (Callon 1998), ou seja, como a Economia ${ }^{3}$ performa, molda, formata a economia e não apenas observa como ela funciona. Isso implica considerar como o conhecimento econômico - teorias, técnicas, formas de cálculo, de mensuração e técnicas e tecnologias de gestão -, materialidades - como documentos, softwares, computadores, produtos - e profissionais, empresas, consultores, consumidores entrelaçam realidades econômicas.

Uma das críticas à ideia de performance nos estudos sociais da economia é que essa perspectiva analítica coloca demasiada ênfase na descrição de processos e a na teoria econômica. De fato, quando se trata da temática da inovação, ainda persiste nos estudos da economia um conceito de inovação como algo simplesmente novo que vem à vida por um esforço de agenciamentó .

Existe uma demanda por estudos capazes de ir além da descrição de técnicas, conceitos, processos, materialidades e racionalidades e capturar não só como coisas, ideias e pessoas são agenciadas pela economia, mas como ideias que não são concebidas necessariamente dentro do espectro da racionalidade econômica são postas em movimento com implicações econômicas, políticas e subjetivas. Isso implica refletir sobre as próprias fronteiras do método etnográfico nos estudos sociais da economia.

Esse é o ponto de partida da reflexão que proponho neste artigo, mobilizada por minha experiência etnográfica em empresas de tecnologia brasileiras. Bicharia é uma plataforma digital ${ }^{5}$ que foi ao ar no final de setembro de 2012, reunindo projetos ligados ao bem-estar animal em busca de financiamento coletivo. Fruto do comprometimento afetivo de seus idealizadores com a causa animal, foi fundamentado em um modelo de produção de capital através da agregação de múltiplas fontes de financiamento chamado crowdfunding.

Crowdfunding é um modelo de negócio baseado em transações financeiras de longa distância e sistemas de micropagamento que permitem captar, gerir e distribuir dinheiro a baixo custo que opera por uma lógica de doação espontânea. Hoje, sistemas de crowdfunding se tornaram uma opção acessível a qualquer pessoa interessada em promover campanhas de arrecadação de recursos financeiros para os mais variados fins.

Os agentes de Bicharia negam qualquer caráter filantrópico. Para eles, a plataforma se coloca como uma ferramenta ${ }^{6}$ que permite aproximar doadores e projetos que necessitam de recursos. Um negócio. Entretanto, o que me pareceu cada vez mais claro durante minha convivência com a equipe é

\footnotetext{
3 Faço uso do termo Economia com letra maiúscula para diferenciar a disciplina econômica de economia como uma racionalidade plural e diversa que opera dinâmicas de alocação de recursos, política e poder.

4 Uma leitura importante sobre como o tema da inovação passou a pautar estudos contemporâneos da economia pode ser encontrada em Akrich, Callon \& Latour (2002).

5 Plataforma é um conceito utilizado no mercado de tecnologia para descrever um espaço digital no qual são criados e desenvolvidos conjuntos de distintas mídias que operam simultaneamente, de forma a criar um ambiente de trocas que se retroalimenta.

6 Ferramenta é uma categoria nativa. Programadores, empresários e designers no mercado de tecnologia costumam se referir a negócios como ferramentas, no sentido de que esses arranjos são pensados para “resolver problemas de mercado". A ideia implícita na noção de ferramenta é uma disposição ativa de intervenção econômica, que acontece por meio de um recurso técnico "neutro", isento de outra intenção além de "resolver problemas".
} 
que o site era muito mais do que um simples negócio. Estava em jogo não somente um investimento de tempo e dinheiro de seus idealizadores, mas principalmente a possibilidade de "viverem seus sonhos".

Bicharia é um exemplo evidente do modo como empreendimentos são pensados nesse panorama de inovação no alto capitalismo. $\mathrm{O}$ efeito que essa nova gramática provoca é exatamente apagar as fronteiras entre a ação econômica interessada e o projeto de autorrealização pessoal, justificando a intervenção técnica e econômica como um meio para tornar $o$ "mundo um lugar melhor".

A questão que parece se colocar diante de nós é esta: no que exatamente estamos nos tornando à medida que pensamos a nós mesmos como agentes de criação e inovação em um mundo pleno de novas possibilidades?

Meu objetivo neste artigo é explorar como a ideia de inovação permite não só que coisas sejam amalgamadas de forma a compor um arranjo econômico, mas sobretudo opera colocando em movimento ideias que antes não eram compreendidas dentro do escopo da ação econômica. Categorias impregnadas de subjetividade passaram a integrar o cotidiano de empresas como Bicharia. De que forma os "sonhos", as "inspirações" e as intenções de "fazer o mundo um lugar melhor" se convertem em modelos de negócio, técnicas de gestão, estratégias de produção de valor e distintas subjetividades econômicas?

Grande parte dos dados aqui apresentados foram extraídos da etapa de planejamento e lançamento do site, entre meados de agosto e final de outubro do ano de 2012. Essa é uma escolha que privilegia acompanhar o esforço de seus agentes em trazer ao mundo sua visão de negócios. Não tenho a pretensão de esgotar, neste artigo, essa temática fascinante que extrapola o campo etnográfico imediato e nos serve para pensar questões sobre os modos de produção do alto capitalismo contemporâneo. Minha contribuição para esse debate é colocar em questão, a partir da experiência desses sujeitos, modos particulares a partir dos quais essa dimensão da economia é agenciada, imersa nas contingências dos fluxos das práticas, e suas implicações políticas.

\section{Os bichos na beira da estrada}

A história de Bicharia começa na estrada. Assim João ${ }^{7}$ definiria, em nossa primeira reunião conjunta. Tudo começou, ele dizia, quando passou a utilizar seu automóvel para realizar trajetos de casa para o trabalho. Na época ele morava no município de Parobé, região metropolitana de Porto Alegre, e se reunia com a equipe de programação e software na empresa em que trabalhava em um bairro nobre da cidade de Porto Alegre.

$\mathrm{Na}$ travessia, via um cenário de desolação. Animais atropelados, motoristas indiferentes aos "bichos da estrada". Isso o motivou a refletir se existiria alguma maneira de "fazer alguma coisa" para modificar a realidade desses "bichos da estrada”. Foi em um desses dias que ele comentou com seu chefe Gabriel a respeito de uma ideia para uma plataforma digital onde pessoas poderiam oferecer serviços voluntários: lares temporários, ração, roupas, medicação. Especialistas na área de comportamento e saúde animal poderiam fazer "a ponte entre as pessoas dispostas a ajudar e os animais" que, por sua vez, 
ganhariam descontos em serviços especializados. Eles logo descartaram essa idéia. "Muita gente envolvida para dar certo".

Gabriel sugeriu o formato de Bicharia como é hoje: um modelo de negócio crowdfunding formado por projetos, uma "ideia mais empresarial, para ganhar dinheiro de alguma forma”. Agora eles seriam os intermediários entre as pessoas e os animais. Bicharia foi pensado para ser um outro "produto" de sua empresa de tecnologia. Para isso, tiveram que montar uma equipe composta por dois programadores e um designer, Walter, além de João e Gabriel.

João é programador. Ele é o responsável técnico da agência digital. Nunca passou por uma universidade, aprendeu tudo o que sabe por si mesmo e com auxílio de cursos técnicos. Com pouco menos de 30 anos, é casado e morador da região metropolitana de Porto Alegre, município de Viamão. Ele tem um profundo sentimento de gratidão para com Gabriel, segundo ele o único que realmente acreditou em seu potencial como profissional. João era encarregado de fazer as coisas funcionarem e esses aspectos técnicos nem sempre são evidenciados publicamente. Participava da reunião outro membro da equipe, também programador e desenvolvedor, que sairia da empresa meses depois.

Gabriel possui formação em sistemas de informação e negócios, com MBA em gestão estratégica de tecnologia da informação e ciência da computação. Morador da cidade de Porto Alegre, sua maior experiência como funcionário foi em outra empresa digital, que considerou bastante negativa. Foi isso que o motivou a abrir sua própria agência digital. $\mathrm{O}$ sócio da empresa é seu pai, que financiou sua abertura e investimento inicial.

Gabriel assumia para si o papel "empreendedor" e "líder criativo" dessa nova organização. No ideário do empreendedor ${ }^{8}$ do mercado digital, mais importante do que diplomas é seu talento para convencer pessoas de sua aptidão para inovação. Gabriel costumava dizer para mim que um nível muito elevado de especialização compromete a qualidade de suas “ideias e propostas”, já que tira a espontaneidade das "boas ideias".

A todo momento evocava a importância do "saber fazer", de pensar as coisas "na realidade dos mercados". Para ele, não somente construir um produto reconhecido por seu caráter de novidade parecia fonte constante de preocupação e angústia, mas também existia uma crescente demanda expressiva para ele próprio ser visto como um profissional de inovação.

Em sua relação com João, ele parecia assumir um lugar de risco e capacidade de vislumbrar oportunidades de negócio. Existia um esforço de sua parte para cultivar uma sensibilidade quase intuitiva para "fazer dinheiro" e "inspirar" e "motivar" não só a equipe, mas todas as pessoas que entravam em contato com ele, e convencê-las de que esse era um grande negócio em potencial. Fundamentalmente, empreendedor seria um sujeito que "sabe prever, pressentir, farejar" (Boltanski \& Chiapello 2009:145) qual será a próxima grande ideia de negócio e que "sabe prestar atenção nos outros para detectar os indícios que lhe permitirão intervir com discernimento em situações de incerteza” (idem: 146). Em suma, um visionário.

8 Entendo o termo empreendedor como uma categoria nativa. Não é o objetivo deste artigo debater especificamente a figura do empreendedor, mas essa discussão será desenvolvida em artigos futuros. 
Disso dependia sua capacidade de atrair profissionais e investidores. Eles precisavam ser contaminados por essa promessa de sucesso e querer fazer parte disso. Em um cenário de empresa nascente, a aparência de sucesso parece fundamental, uma vez que não existe registro de operaçóes que possa basear qualquer decisão de negócio ou até mesmo projeção de rendimentos.

Isso me leva a pensar na palavra performance em um duplo sentido, tanto de eficácia como de dramaticidade, como bem coloca Anna Tsing (2004) em sua proposta conceitual de uma economia das aparências. Ela nos diz que "in speculative enterprises, profit must be imagined before it can be extracted; the possibility of economic performance must be conjured like a spirit to draw an audience of potential investors" (idem :84). Isso exige de seus agentes um fazer consciente de si mesmos como um espetáculo, construindo uma narrativa persuasiva capaz de afetar investidores, profissionais e consumidores e, assim, atrair capital e recursos para seus empreendimentos.

Essa relação entre eficácia e dramaticidade foi presente ao longo de todo o trabalho de campo. Os agentes de Bicharia faziam grandes esforços para dramatizar seus sonhos. Quando João falava sobre os "bichos da estrada”, era possível imaginar aquele cenário de desolação do qual tanto falava.

Era uma cena que afetava os sentidos, fazia emergir memórias e sensações e provocava uma experiência de impotência. Essa afetação justificava a existência de Bicharia. Quem escutava sua história parecia compelido a concordar com a necessidade da existência da empresa e que ela teria um grande impacto sobre a realidade que João descrevia. Categorias do sensível adquiriam essa dupla conotação de eficácia e dramaticidade, agenciadas de modo a canalizar recursos para o novo empreendimento.

\section{A construção de uma consciência da audiência}

Depois da ideia de desenvolver um crowdfunding voltado para projetos que envolvem bem-estar animal, eles logo começariam a trabalhar. Inicialmente, criariam uma landing page ${ }^{9}$ onde pessoas poderiam curtir a página no Facebook e informar dados de contato para que eles pudessem avaliar a aceitação da proposta e começar a criar um público.

Assim que Bicharia estivesse pronto, eles já teriam constituído uma audiência inicial que poderia prover doações, assim como obter um perfil de usuário que pudesse nortear suas ações. Sem esses dados, Bicharia seria um plataforma inviável. Era necessário diminuir a incerteza no momento de lançamento desse produto digital com base em dados quantitativos que permitissem construir uma consciência da audiência, sujeitos imaginados por eles como um tipo de "usuário ideal", com personalidade, gênero, idade, gostos e interesses próprios. Esse "usuário ideal" era pensado como um apoiador, alguém que compartilhava os mesmos sonhos e as mesmas visões de futuro que os idealizadores de Bicharia.

Desse modo faziam sentido do que antes era uma massa inominada de potenciais doadores. $\mathrm{O}$ modelo de "usuário ideal" passou a nortear o modo como passaram a se comunicar com essa base de audiência, adequando seu modo de falar, agir, escolhendo mídias diferentes para mediar esse contato.

Tudo isso faz parte, para eles, de um conglomerado chamado "interface". O artifício da mediação, se antes era naturalizado no curso de ações, ficaria exposto no modo de produção de Bicharia.

9 Landing page é a página de destino ou página de entrada. O primeiro local por onde o visitante chega em um site. 
Parecia muito claro para todos os agentes a necessidade de "entrar no mundo" da "audiência", parecer-se "com eles", falar a "sua língua"; somente assim poderiam convencê-los de sua seriedade, atrair projetos, investidores e aumentar o número de potenciais doadores.

Eles não estariam apenas desenvolvendo um produto digital, mas criando uma marca ${ }^{10}$ que proporciona uma experiência do usuário: a vivência afetiva e sensorial como veículo de articulação das relações com o outro e consigo mesmo, um mecanismo de instrução e educação da mente e do sentir ${ }^{11}$. A relação com o usuário era também uma relação de performance em duplo sentido. Ao dramatizar categorias do sensível e do self, os agentes de Bicharia conseguiriam atrair cada vez mais usuários para o site. Essa imagem do usuário não aparecia para eles como algo figurativo, mas como números, gráficos e estatísticas.

Eles ressaltavam a todo momento a distância entre o que seria para eles um "consumidor" e um "usuário". A noção de consumidor parecia muito atrelada ao ato de compra de mercadorias que pouco interferia na esfera da produção, ao passo que a ideia de usuário diria respeito a um agente que possui ação direta na estrutura do projeto digital. Usuário modifica constantemente a plataforma digital por meio de sua ação no site: ele é visto como produtor tanto quanto a equipe responsável por colocá-lo no ar, ele faz coisas que provocam efeitos concretos. Isso significa que o ato de consumo também era pensado por eles como um ato de produção. Mobilizar os usuários com sua visão de marca era também trazê-los para dentro do processo produtivo.

\section{Um empreendimento emocional}

Era uma época empolgante, eles diziam. O fluxo de novos trabalhos na empresa da qual faziam parte estava estagnado. Bicharia se tornou a principal preocupação dos dois, uma "promessa de sucesso". No entanto, não bastava apenas os dois acreditarem no sucesso. Era preciso que outras pessoas fossem contaminadas por essa promessa.

Gabriel havia entrado em contato com alguns empresários e investidores que poderiam financiar o site, mas não obteve nenhuma resposta positiva. Ele dizia que era muito difícil conseguir acesso a financiamento desse tipo sem ter "contatos quentes", já que uma "boa ideia só seria suficiente se estivesse endossada pelas pessoas certas". Muito estava em jogo: Bicharia poderia representar a falência definitiva da empresa e de tudo o que João e Gabriel construíram juntos.

Poderia soar paradoxal seu entusiasmo em contraste com a situação financeira da empresa. Uma possível abordagem talvez fosse um tanto pragmática. Gabriel tinha que convencer a equipe do sucesso potencial da plataforma, pelos meios que lhe cabiam. Enquanto líder criativo do projeto, esperar-se-ia dele uma demonstração de "perícia", "visão de negócio", capacidade de gerar novas idéias e manter o grupo coeso e voltado a algum objetivo determinado; no entanto, sua capacidade de respon-

10 Por meio da matriz teórica da antropologia do consumo, compreendo marca enquanto operador simbólico que medeia noções de identidade, regula relações sociais e situa um dado bem ou serviço dentro de um referencial classificatório, investido de aspectos valorativos que provocam fluxos e permanências. Podemos compreender a noção de interface também por esse viés.

11 A articulação de um debate acerca da sensibilidade, sensualidade e sexualidade Ocidentais, e sua íntima relação com a constituição dos campos artísticos, de entretenimento e industrialização do lazer pode ser acompanhada por meio de Duarte (2004) e Campbell (2001). 
der a essas demandas não era vista de maneira unânime entre a equipe, muito devido à falta de investidores. Mesmo assim, todos estavam extremamente motivados para fazer Bicharia funcionar, de uma maneira até mesmo contagiante.

Enquanto estava entre eles, a possibilidade do site ser um fracasso parecia muito distante. Estavam radiantes, queriam comentar cada detalhe de sua trajetória de trabalho, as pequenas descobertas do cotidiano, comentários de pessoas com quem conversaram sobre sua ideia. Parecia ser mais do que um simples esforço em me convencer do sucesso que os aguardava. Era o que os mantinha juntos.

Existia uma demanda afetiva implícita no curso de suas ações. A expressão das emoções possuía um papel preponderante nesse arranjo empresarial, de modo a tornar parte do trabalho o exercício ativo dos afetos. Parecia necessário que todos estivessem em uma sintonia sutil, compartilhando de uma mesma esperança de sucesso. Era necessário dramatizar essa esperança na forma de entusiasmo e otimismo, mesmo que as perspectivas parececessem menos promissoras. Esse não era um mero exercício expressivo. Os sujeitos pareciam educar os modos de sentir como uma estratégia de gestão das emoções. Não bastava acreditar que o negócio ia dar certo, era necessário expressar e sentir o sucesso.

A relação entre afetividade e trabalho nas paisagens do alto capitalismo foi pensada por Arlie Hochschild (2003) em termos de um trabalho emocional que requer "one to induce or suppress feeling in order to sustain the outward countenance that produces the proper state of mind in others", e que, além de criar "a publicly observable facial and bodily display" (2003:7), é passível de ser convertido em dinheiro na forma de vendas, de negócios, de salários, ou seja, possui valor de troca.

Os afetos eram incorporados a um léxico econômico e empresarial de modo a tornar esses arranjos econômicos emergentes eficazes. Da mesma forma, os sentimentos também podiam emergir a partir de divergências, conflitos, disputas e fazer pensar sobre implicações que extrapolam o domínio do sensível.

Conforme o negócio tomou corpo, alguns desses sujeitos passaram a relatar para mim em confidência seu desejo de romper o vínculo profissional com o site. Essas conversas geralmente começavam com queixas de ordem afetiva. Eles me diziam estar insatisfeitos com o "caminho que o site estava tomando" e que "sentiam" que "não ia dar certo". Entretanto, eles não falavam simplesmente de "intuições" e "sentimentos". Eles se referiam às decisões de negócio de Gabriel. Eles sentiam em seus corpos e em suas mentes um conflito técnico, político e financeiro.

Gabriel não era alheio a essas opiniões contrárias. Ele percebia a sutil mudança na expressão das emoções de sua equipe. Quando algum profissional passava a agir de maneira "fria" e "racional", Gabriel fazia uso de estratégias para cultivar suas expectativas. Ele passava a dividir relatos de reunióes bem-sucedidas das quais participava, comentários positivos das pessoas sobre Bicharia, a possibilidade de novas oportunidades de negócio. No entanto, a falta de receptividade emocional também o fazia repensar essas mesmas ligações profissionais. 


\section{Crowdfunding é um círculo, não uma linha reta}

João era mais entusiasmado com o sistema que estava construindo. Como crowdfunding "mexeria com pagamento", era algo novo e complexo para eles. A inovação, em sua opinião, estava no mecanismo de checkout $^{12}$. A sistemática de financiamentos coletivos já é muito disseminada entre programadores, desenvolvedores e bastante conhecida de empreendedores digitais. Mesmo que não sejam disponibilizados gratuitamente sistemas-base específicos, metodologias de engenharia reversa são extremamente comuns nessa esfera sociotécnica.

O difícil, dizia João, era desenvolver algo "do zero" ou adaptar modelos preexistentes às novas concepções. O primeiro caso bem-sucedido seria o da plataforma norte-americana Kickstarter, lançada no ano de 2009. Parecia ser consenso entre João, Gabriel e Walter que a primeira iniciativa de adaptar esse modelo no Brasil seria por parte da empresa Catarse, que se tornara sinônimo nacional de crowdfunding, tanto que qualquer plataforma de financiamento coletivo que surge no Brasil é diretamente ligada à sua marca, mesmo que não tenham sido responsáveis por sua construção.

Gabriel e João acreditaram que seria importante, durante a execução dessa primeira fase do projeto, marcar uma reunião com o "pessoal do Catarse" para conversar sobre o Bicharia e pedir sugestões e conselhos em um encontro formalizado. $\mathrm{O}$ modo como tratavam do assunto revelava um misto de deferência e competição. Em agosto de 2012 foram até São Paulo, cidade-sede da empresa, para almoçar com um dos sócios chamado Daniel. Eles descrevem essa experiência de modo muito positivo. Daniel foi solícito e generoso, mas fez um alerta: não tem como ganhar dinheiro com crowdfunding, só se investirem em "serviços periféricos".

Eles diziam que "crowdfunding é um círculo, não uma linha reta”. Isso significa que eles deveriam ser capazes de construir um "ecossistema que se retroalimenta", um cenário ideal onde as pessoas doam e recebem uma recompensa, os projetos por sua vez investem novamente o montante recebido e se inicia mais um ciclo de produção de valor. Um ciclo "virtuoso". Outro ponto importante da conversa com o representante da Catarse foi uma colocação emblemática: fujam do "assistencialismo" "Crowdfunding não é caridade".

Eles não estavam preocupados com o modo como o dinheiro obtido pelas doações seria utilizado, nem queriam dizer aos candidatos como deveriam agir com o montante recebido. No entanto, eles passaram a exigir prestação de contas transparente. Bicharia serviria como chancela de confiança, o intermediário que atestaria a seriedade dos projetos e a transferência de valores. Para tanto, o site não podia trabalhar sozinho. Tinha que contar com a ajuda e com o investimento de todos os interessados em apresentar projetos para financiamento coletivo. Gabriel costumava dizer que as pessoas tinham que "fazer por merecer" o dinheiro levantado no site. Isso significava que elas tinham que investir seu tempo para pensar bem seus projetos e divulgá-los da melhor maneira possível.

Uma grande preocupação de Gabriel era a relação estabelecida entre o site e os responsáveis pelos projetos. Ele temia gerar uma situação de "dependência de projetos". Aqueles que pleiteavam

12 Mecanismo que conduz o usuário para a confirmação e realização da compra no site. 
um espaço no site não poderiam ser "imediatistas", mas pensar em uma quantia que fosse necessária a médio prazo para que o dinheiro não fosse embora tão rápido. Ele não queria que a cada mês o mesmo projeto fosse enviado novamente para Bicharia por causa disso.

Para isso, ele pensou em uma estrutura de padronização dos pedidos de financiamento. Os projetos deveriam cumprir uma série de requisitos. O primeiro era traduzir necessidade em valor monetário. Cada projeto deveria vir com um valor estipulado, discriminado e justificado, associando o valor solicitado a uma série de itens que deveriam ser comprados e serviços que seriam contratados para solucionar o problema proposto dentro de um cronograma de ação.

Cada projeto deveria ser um empreendimento em si mesmo, capaz de comunicar a um público bastante heterogêneo sua importância em termos racionais e monetários para disputar investimento com tantos outros projetos que estariam à disposição na plataforma.

O que está implícito nessa ideia é que os responsáveis por cada projeto deveriam incorporar uma lógica e um léxico econômicos: deveriam passar a pensar em si mesmos como concorrentes em um mercado de doaçôes ${ }^{13}$. O preenchimento do projeto era um processo não somente de incorporação, mas de performance desse saber técnico. Cada pessoa que desejasse ter seu projeto no site deveria demonstrar ser capaz de lidar com esse dinheiro e entender a lógica do financiamento coletivo ${ }^{14}$.

Além do projeto, seus responsáveis também teriam que criar um sistema de recompensas para incentivar doações. Conforme cada faixa de doação, o doador receberia brindes diferentes. A pessoa que doasse mais receberia um brinde de maior "valor" em comparação com aquela que doasse menos. No entanto, deveria ser claro para todos os doadores que essa era uma escolha do responsável por cada projeto. O site Bicharia não poderia tratar de maneira "especial" usuários que doassem mais, para respeitar um princípio de equivalência. Toda divulgação também era responsabilidade de cada responsável por projetos.

Um problema persistia na construção de Bicharia: demonstrar a confiabilidade das transações para o usuário comum. E isso deveria ser efetuado por meio da noção de transparência, ou seja, era preciso conceber mecanismos de visualização de dados de transferência monetária. Para tanto, João

13 A ideia de concorrência de mercado é fundante da teoria econômica. A concorrência idealmente ocorre em um mercado, conceituado como um espaço no qual empresas vendem seus produtos e consumidores os compram, ou seja, onde se estabelecem relações comerciais. O eixo de equilíbrio do mercado é o preço. O preço é a informação fundamental para a qual economistas olham para deduzir a estrutura dos mercados. Em um mercado ideal, nenhuma empresa é capaz de manipular o preço das mercadorias devido à presença de um grande número de empresas que buscam estabelecer trocas com um grande número de consumidores. Consumidores são pensados como agentes racionais e utilitários. Eles possuem informação referente a preço, qualidade e oferta de produtos e agem racionalmente de modo a maximizar os recursos de que dispõem. No Brasil, o Conselho Administrativo de Defesa Econômica (CADE) é uma autarquia federal, vinculada ao Ministério da Justiça, que opera para "zelar pela livre concorrência no mercado". Entretanto, como muito bem explorado por Gustavo Gomes Onto (2016) em sua tese de doutorado defendida no Museu Nacional, intitulada "Ficções econômicas e realidades jurídicas: uma etnografia da política de concorrência no Brasil", a ideia de concorrência aparece mais como um princípio de justiça. No caso de Bicharia, por exemplo, quando um projeto consegue arrecadar um montante maior do que os outros, esse fato é justificado pelo princípio da concorrência. Eles diriam que seus idealizadores trabalharam com mais "dedicação" do que outros, divulgaram extensivamente o projeto, promoveram ações de conscientização, e assim por diante. Em suma: eles foram "mais competitivos". Pensar a concorrência não só a partir dos economistas e juristas, mas no cotidiano dos negócios, é um caminho ainda pouco explorado para pensar a economia.

14 Sobre processos de avaliação e valoração econômica em projetos de empreendimento, uma leitura interessante é o artigo "Formuler les projets d'éntreprise", de Martin Giraudeau (2013). 
implementou o checkout transparente do sistema Moip ${ }^{15}$, que na época "nem o Catarse nem ninguém usava”.

Para ele, era apenas uma questão de tempo alguma outra empresa aproveitar essa inovação. João admite que, duas semanas depois do lançamento oficial do site, o próprio Catarse lançou um outro produto e se aproveitou do que era "a maior exclusividade" deles. Entretanto, o fato de ter sido o primeiro a realizá-la parecia significar algum tipo de conforto afetivo, pois estava seguro de ter criado o sistema "mais simples possível" e que a cópia posterior era uma atestado do reconhecimento de sua habilidade como construtor de sistemas.

Ele havia, em seus termos, criado algo novo, realizado um trabalho criativo, pois tinha sido capaz de resolver um problema especifico. Gabriel não estava tão preocupado com transparência, ao menos do ponto de vista técnico, apesar de enfatizar esse aspecto diante de outros profissionais do mercado digital.

Não bastava Bicharia demonstrar que era transparente, tinha que parecer convincente, inovador e bem sucedido desde o primeiro dia. "Sucesso atrai sucesso", ele dizia. Ninguém vai acessar um site que mais parece uma cidade fantasma. Era preciso demonstrar perícia, força, popularidade. $\mathrm{E}$ isso poderia ser feito por meio de uma interface amigável e vendedora. Apesar desse reconhecimento, isso não foi levado adiante por ele. Agora era motivo de deboche entre todos o fato de ele ter comprado um layout pronto, branco, azul e cinza, "totalmente masculino", nas palavras de João. Entretanto, isso iria passar despercebido se não fosse a intervenção inesperada de Walter nesses primeiros estágios de Bicharia.

\section{O valor da interface e do expert digital}

Walter já teria sido contratado pela empresa de Gabriel em diversos projetos. Entre eles, nenhum contrato de prestação de serviço. Todas as demandas profissionais eram negociadas informalmente. Ele e João eram amigos. Essa amizade surgiu entre um trabalho e outro e parece ter sido ainda mais fortalecida pelo Bicharia.

A entrada de Walter na equipe Bicharia era celebrada por todos e não faltavam elogios a ele. "Foi o momento em que tudo mudou", me diziam Gabriel e João. Em uma de suas muitas conversas informais, João comentou a idéia do financiamento coletivo com ele em agosto, antes do lançamento oficial. Walter logo se interessou e os dois começaram a trocar comentários gerais sobre o andamento do projeto.

Quando estava pronto, João enviou para Walter o link protegido. O que saltou aos olhos dele nesse primeiro momento foi "a falta de interface". Ele me disse que aquele layout comprado "totalmente masculino" o irritou profundamente, especialmente pelo fato de Gabriel não ter lembrado dele como designer disponível para assumir a tarefa.

Além disso, como seria possível alguém confiar em um site cuja interface era comprada pronta? Qualquer profissional saberia rastrear sua origem, o que enfraqueceria consideravelmente sua reputa-

15 Ver site https://site.moip.com.br. 
ção. Motivado pela frustração, Walter se ofereceu para construir a interface de Bicharia. Coincidentemente, Gabriel ficou muito doente nesse intervalo entre o projeto inicial e o desenvolvimento para o lançamento e chegou a ficar hospitalizado por quase um mês, contando suas entradas e saídas.

Foi a presença de Walter que garantiu a confiança da equipe: "sem ele estaríamos perdidos", constantemente me diziam. A primeira grande mudança proposta foi com relação ao gênero de Bicharia.

Walter defendia que, por algum motivo, esse seria um site "feminino" e a representação gráfica deveria seguir formas e cores de acordo com esse padrão. Então, ele criou uma marca que mostrava um cãozinho com cartola, não só para mostrar que os animais são "tão humanos quanto nós", mas também porque imaginava a marca Bicharia como algo que apela para a "generosidade", a "fofura" e a "gentileza". A marca, tal como a audiência, era pensada tal como um indivíduo.

Ele não soube racionalizar plenamente essa "intuição". Autores preocupados com a relação humano-animal já atentam para fenômenos de docilização canina e felina, assim como a ampliação de tecnologias de intervenção em seus corpos. ${ }^{16}$

Walter não possuía um olhar informado pela teoria. No entanto, estava produzindo uma abstração afinada com esses paradigmas, um modelo teórico que nortearia a construção desse artefato digital. Quando ele apresentou a idéia para João e Gabriel, eles logo foram conferir em seus gráficos de audiência e ficaram surpresos com a precisão da "leitura de mercado" do designer. Ele estava certo: 75\% dos indivíduos cadastrados previamente eram mulheres e esse padrão persiste até hoje nas interações com o site e nas doações efetuadas. $\mathrm{O}$ apelo afetivo do cãozinho foi tão grande que não demorou para aparecerem e-mails pedindo a criação de camisetas, canecas e pôsteres do Bicharia, artigos que viriam a representar mais um braço da marca.

O modelo proposto mostrou-se eficaz para produzir valor de mercado e Walter se legitimaria frente aos colegas como criativo e se tornaria um recurso imprescindível. A relação com Walter era algo a ser cultivado e celebrado. Ele havia se tornado um ativo econômico, um recurso importante para tornar Bicharia um site competitivo no mercado de tecnologia.

Walter não se considerava autor da interface que alçou Bicharia ao "sucesso", nem ao menos tomava seu trabalho como realmente criativo. Ele afirmava que só colocou coisas que já existiam juntas e que era um interprete de "tendências de mercado". Só estaria satisfeito com seu trabalho na medida em que fosse capaz de oferecer continuamente respostas a esse mesmo "mercado", em um processo de constante aperfeiçoamento de si motivado pelo orgulho de um "trabalho bem feito".

Isso se assemelha muito ao entusiasmo demonstrado por João durante a construção do sistema da plataforma. Ambas as atividades dependiam de suas mãos. Passavam horas diante das telas dos computadores, em um ajuste minucioso de códigos e pixels, aperfeiçoando processos e gestos técnicos. Isso em muito contribuiu para a formação de sua relação de amizade. Durante as longas horas de trabalho noturno, conversavam e trocavam experiências.

16 Sobre docilização animal, ver Segata (2012). 
Não seriam apenas habilidades que estavam sendo lapidadas, mas competências cognitivas e gestuais. Isso abre um caminho fortuito para pensarmos em construção de expertise enquanto a formação de uma sensibilidade e cognição incorporadas.

Walter via a si mesmo como um artesão, tal como João. Existia entre eles uma identificação que nascia da ideia de que o trabalho seria executado por "prazer, por diversão e, é claro, pelo reconhecimento de seus pares de que se é um talentoso e habilidoso construtor" (Leitão 2012:270). Esse não era o mesmo modo como Gabriel concebia a si mesmo, fato que tornou-se ainda mais evidente à medida que Bicharia adquiria visibilidade nacional.

\section{A construção do criativo digital}

Nas três primeiras semanas após o lançamento oficial do site, já era evidente sua repercussão. Veículos de mídia como Globo.com, Superinteressante, Revista Galileu ${ }^{17}$, Site Abduzeedo, Caderno Link da Folha de São Paulo e o Jornal Correio do Povo ${ }^{18}$ foram os primeiros a publicar textos e imagens de divulgação do projeto.

Bicharia se tornou uma marca capaz de atrair a atenção dos usuários, profissionais do mercado digital, projetos ligados ao bem-estar animal e, mais importante, investidores e patrocinadores. Logo os conselhos de Daniel iriam fazer sentido para Gabriel. Ele se encarregou de divulgar oficialmente Bicharia e se prontificou a selecionar todos os projetos oferecidos à plataforma, assim como estabelecer contato com empresários do setor e responder às dúvidas enviadas pelos usuários, e logo percebeu a exigência dessas tarefas.

Uma das coisas que o incomodavam era a "baixa qualidade" dos projetos enviados. Nada parecia estar de acordo com as normativas de projetos que ele havia criado. O que mais via eram propostas de caridade que apelavam a uma retórica de vitimização animal: "Ajude os cachorrinhos, eles vão morrer". Para ele, isso só ia gerar pena e não ação.

Ninguém é motivado a doar dinheiro por pena, pensava ele. A pena transparece em sua fala como um sentimento de paralisia que se opõe à ação. Podemos pensar a pena como uma resposta emotiva possível dentro da gramática moral de merecimento que surge diante de uma assimetria instransponível entre dois seres. Só se sente pena daquele que não pode ser ajudado. Que não tem poder algum. Que se encontra em um estado de vulnerabilidade tal que se torna dependente da ajuda dos outros.

Sua grande queixa era que muitos não conseguiam "entender" a proposta de negócio Bicharia. Achavam que era um site filantrópico. Quando mais o site se tornava conhecido, mais conflitos emergiam. Um usuário chegou a acusá-los de desvio de verbas e outras pessoas reclamavam da porcentagem que ficaria com os proprietários do site, pois consideravam que isso seria "lucro". Como é possivel lucrar com a mazela dos bichinhos? - questionavam.

17 http://revistagalileu.globo.com/Revista/Common/0,EMI321599-17770,00-SITE+BRASILEIRO+ ABRE+CROWDFUNDING+PARA+PROJETOS+COM+ANIMAIS.html. Acesso em 19 de agosto de 2013.

18 http://www.correiodopovo.com.br/blogs/maispreza/?p=7010 Acesso em 19 de agosto de 2013. 
O que parte do público não conseguia perceber era o caráter comercial de Bicharia. O que parecia lógico para seus agentes não era assim tão evidente para sua audiência. Como qualquer negócio, o site precisaria de rendimentos para sua manutenção e para pagar funcionários. Gabriel revelou que a porcentagem que ficava com sua empresa era apenas suficiente para manter esses gastos fixos. Ele "não fazia dinheiro" com a plataforma.

Um fato inesperado foi que a divulgação não criou o número de acessos imaginado. A notícia no portal Globo.com, por exemplo, não chegou a gerar mil acessos no dia de sua publicação. Gabriel pensou em mudar de estratégia. Ele acreditava que era preciso convencer celebridades envolvidas na causa animal a divulgar o site. Esse seria seu projeto dentro do Bicharia: relacionamento com formadores de opinião. Para conseguir isso, pensava em estratégias de contato mediado por presentes e brindes exclusivos, assim como agradecimentos públicos elogiosos. Mas isso, em sua concepção, não seria suficiente. Era necessário "dar uma cara" para o site, ou seja, ele pretendia assumir "a face”, a "autoria" do projeto, aparecendo em entrevistas e pronunciamentos diversos. Isso nos remete à noção de "serviços periféricos", como explorada por Daniel.

Para motivar mais doações e envio de projetos dentro do padrão normatizado pelo site seria preciso investir na "marca" Bicharia: tratá-la como "case" do mercado digital e, assim, comercializá-la como um "serviço periférico".

Isso significava oferecer palestras, participar de eventos, ministrar aulas inaugurais em universidades, criar linhas de produtos e outros serviços adequados ao ecossistema gerado pelo site. Era preciso adquirir prestígio entre pares e impressionar ouvintes. E esse era um papel exigente que Gabriel estava disposto a assumir. Passaria agora grande parte de seu tempo construindo relações e, consequentemente, a si mesmo enquanto criativo do mercado digital em um processo de crescente demanda expressiva e performática.

Caso Bicharia tivesse que acabar, restaria a identificação gerada pela ampla circulação de seu nome e face ${ }^{19}$. Nos bastidores permaneciam João e Walter, que pareciam ter consciência da assimetria produzida nesse processo e posicionavam-se de forma crítica. A construção da figura do empreendedor inovador parecia representar uma ruptura nas relações colaborativas anteriormente estabelecidas para produzir esse coletivo heterogêneo de práticas e saberes e a conformação de uma nova rede relacional (Strathern 1996).

\section{Reflexões finais}

Bicharia não era simplesmente um site para seus idealizadores. Sua existência significava a expansão das fronteiras da economia de mercado e a produção de um conjunto de técnicas e tecnologias de intervenção econômica, justificadas por uma questão socioambiental urgente de nosso tempo. Para eles, Bicharia aparecia como uma possibilidade de tornar sua visão de mundo uma experiência pragmática. O que aparece muitas vezes implícito nas falas desses sujeitos é a crença no poder inovador da economia para resolver questões do social.

19 Para acompanhar uma discussão sobre fama, ver Munn (1992). 
Essa otimista busca por autossatisfação criativa não anularia, no entanto, a constituição de novas assimetrias de poder e a aderência a antigas lógicas hierárquicas. A relação entre a emergência da figura do líder criativo e a do expert digital explicitam uma nova dinâmica de acúmulo diferencial de prestígio e renda. Da mesma forma, as relações aparecem como recurso necessário à captação de dividendos e talentos e constituem um terreno sensível e, por vezes, perigoso. Seria preciso, por vezes, oscilar entre convenção e invenção, entre sentido e poder, entre liberdade e expressividade, em uma busca por estabilizar as tensões inerentes a esse arranjo emergente.

Algo que me impressionou particularmente em Bicharia foi o modo como status, expertise e Mercado $^{20}$ aparecem inter-relacionados de maneira altamente complexa, dinâmica e repleta de nuances. A figura que encarna o capitalismo não é mais vista como aquela que busca a produtividade, a eficiência, a eficácia, os métodos, a engenharia de produção. $\mathrm{O}$ empreendedor é um agente que se pensa como aquele que entusiasma a todos com sua visão de futuro. Agir economicamente no mundo é agir de acordo com suas profundas inspirações e o sucesso financeiro é resultado não de estratégias concretas, mas da capacidade de novas ideias de ressoar profundamente com os anseios, desejos e com a subjetividade daqueles que compõem os mercados.

Questionar a idéia da economia como inovação tecnológica é, portanto, refletir sobre os modos como a economia passa a agenciar o social e a subjetividade. A potência crítica da etnografia está exatamente em levar a sério o que esse arranjo entre coisas, ideias e pessoas efetivamente produz no mundo e suas implicações não somente políticas e econômicas, mas sobretudo subjetivas.

\section{Louise Scoz Pasteur de Faria é doutoranda em Antropologia Social pela Univer- sidade Federal do Rio Grande do Sul e Assistente de Pesquisa no Departamento de Cultura Material da University College London (UK).}

\section{REFERÊNCIAS BIBLIOGRÁFICAS}

AKRICH, Madeleine; Michel Callon; Bruno Latour. 2002. "The key to success is innovation, part I: The art of interessement”. International Journal of Innovation Management 6(2):187-206.

BOLTANSKI, Luc \& Ève Chiapello. 2009. O novo espirito do capitalismo. São Paulo: Martins Fontes. Gallimard.

\& Laurent Thévenot. 1991. De la justification: les économies de la grandeur. Paris: Éditions

CALLON, Michel. 2013. “Qu'est-ce qu'un agencement marchand?”. In: M. Callon et al. Sociologie des agencements marchands. Paris: Presses des Mines.

CAMPBELL, Colin. A ética romântica e o espirito do consumismo moderno. Rocco: Rio de Janeiro, 2001.

20 Utilizo o termo Mercado com inicial maiúscula como estratégia de diferenciação entre mercado como economia de mercado e mercados como instâncias de troca. Os agentes de Bicharia acionam a ideia de Economia de Mercado para justificar toda sorte de procedimentos técnicos e arranjos empresariais. 
DUARTE, Luiz Fernando Dias. 2004. “A pulsão romântica e as ciências humanas no ocidente”. RBCS 19(55).

FEENBERG, Andrew. 2014. Pour une théorie critique de la technique. Quebéc: Lux Éditeur.

GIRAUDEAU, Martin. 2013. “Formuler les projets d'entreprise”. In: François Vatin (dir.). Évaluer et valoriser. Une sociologie économique de la mesure. Toulouse: Presses Universitaires du Mirail.

HO, Karen. 2009. Liquidated: An ethnography of wall street. Duke University Press: Durham and London.

HOCHSCHILD, Arlie R. 2003. The managed heart: commercialization of human feeling. Berkeley: University of California Press.

HOLMES, Douglas. 2014. Economy of Words: Communicative Imperatives in Central Banks. Chicago: University of Chicago Press.

LEITÃO, Débora Krischke. 2012. "Entre primitivos e malhas poligonais: modos de fazer, saber e aprender no mundo virtual Second Life”. Horizontes Antropológicos 38: 255-285.

MACKENZIE, Donald. 2009. Material markets: how economic agents are constructed. Oxford: Oxford University Press.

MIYAZAKI, Hirokazu. 2013. Arbitraging Japan: dreams of capitalism at the end of finance. Los Angeles: University of California Press.

.2006. "Economy of Dreams: hope in global capitalism and its critique". Cultural Anthropology 21(2):147-172.

.2004. "Hope as a method". In: . The method of hope: anthropology, philosophy and Fijian knowledge. Stanford: Stanford University Press.

MUNN, Nancy. 1992. The fame of Gawa: a symbolic study of value transformation in a Massim (Papua New Guinea) Society. Durham: Duke University Press.

ONG, Aihwa \& Stephen Collier. 2005. Global Assemblages: Technology, Politics and Ethics as anthropological problems. Malden: Blackwell Publishing.

ONTO, Gustavo Gomes. 2016. Fiç̧ôes econômicas e realidades jurídicas: uma etnografia da política de concorrência no Brasil. Tese de doutorado. Rio de Janeiro: Museu Nacional/PPGAS.

POLANYI, Karl. 1994. A grande transformação: as origens da nossa época. Rio de Janeiro: Campus.

RILES, Annelise. 2011. Collatreal Knowledge: Legal Reasoning in the Global Financial Markets. Chicago: University of Chicago Press.

ROYVIK, Emil. 2011. The Allure of Capitalism: An Ethnography of Management and the Global Economy in Crisis. Berghahn Books: New York.

SEGATA, Jean. 2012. "Uma nova epidemia: a depressão canina e os seus dispositivos”. Trabalho apresentado na 28'. Reunião Brasileira de Antropologia. São Paulo/SP, 2 a 5 de julho.

STRATHERN, Marilyn. 1996. "Cutting the network". Journal of the Royal Anthropological Institute 2(3):517-535.

TSING, Anna. 2004. "Inside the economy of appearances". In: A. Amin \& N. Thrift (eds.). The Blackwell Cultural Economy Reader. Oxford: Blackwell Publishing. 


\title{
SUA DOAÇÃO É MEU NEGÓCIO: UMA ETNOGRAFIA EM UM EMPREENDIMENTO DE CROWDFUNDING BRASILEIRO
}

Resumo:Viver os sonhos. Mudar o mundo. Fazer acontecer. Expressóes impregnadas de moralidade e subjetividade passaram a compor a gramática das paisagens empresariais contemporâneas, associadas fortemente a uma idéia de inovação como fluxo contínuo e criativo de idéias, coisas e pessoas que colocam "o novo" em movimento. Falar em inovação pode parecer muitas vezes parte de uma narrativa dispersa e desincorporada que reifica noções de eficácia, produtividade e racionalidade econômica. Isso, no entanto, não conduz a uma reflexão densa a respeito dos modos através dos quais a economia é pensada, feita e imaginada no curso da vida. A partir de uma etnografia de um empreendimento de tecnologia crowdfunding brasileiro, busco apreender como essa gramática da inovação é agenciada e suas implicações econômicas, políticas e subjetivas.

Palavras-chave: Antropologia econômica; inovação; agenciamento; subjetividade; criatividade.

\section{YOUR DONATION IS MY BUSINESS: ETNOGRAPHY IN A BRAZILIAN CROWDFUN- DING VENTURE}

\begin{abstract}
Live the dream. Change the world. Make it happen. Expressions impregnated with morality and subjectivity are now part of the landscape of contemporary business, strongly associated to an idea of innovation as a continuous and creative flow of ideas, things, and people that bring out the "new". Speaking of innovation may seem often a scattered and disembodied narrative that reifies notions of productivity, effectiveness and economic rationality. Nevertheless, this does not allow a profound reflection on the ways economy is thought, made and imagined in the course of life. Based on an ethnography of a Brazilian crowdfunding enterprise, I seek to understand the ways in which this grammar of innovation comes to life as an effort of enactment, and its economic, political, and subjective implications.
\end{abstract}

Keywords: Economic anthropology; innovation; agencement; subjectivity; creativity.

RECEBIDO: $18 / 08 / 2016$

APROVADO: 04/04/2017 